\title{
Correction to: The prognosis in palliative care study II (PiPS2): study protocol for a multi-centre, prospective, observational, cohort study
}

Anastasia K. Kalpakidou', Chris Todd², Vaughan Keeley ${ }^{3}$, Jane Griffiths ${ }^{2}$, Karen Spencer², Victoria Vickerstaff', Rumana Z. Omar ${ }^{4}$ and Patrick Stone ${ }^{1 *}$

\section{Correction}

After publication, the authors noticed some minor errors in "Nested qualitative sub-study" section, first paragraph of the section, page 7 of the published article. These may cause some confusion to the readers when the results of the qualitative sub-study are published [1].

Please see below for details (the new text has been added in bold and the incorrect text has been underlined.

"It was anticipated that semi-structured, face to face interviews were would need to be conducted with a purposive sample of approximately 15 patients, 15 carers and 15 clinicians to determine the acceptability of using prognostic indicators, and barriers and facilitators to clinicians' use. It was recognised that, data saturation will would determine the final sample sizes, which may be larger or smaller than anticipated. To date, 28 patients, 19 carers and 32 clinicians were have been enrolled in the qualitative sub-study."

\section{Author details}

${ }^{1}$ Marie Curie Palliative Care Research Department, Division of Psychiatry, UCL, 6th Floor, Maple House, 149 Tottenham Court Road, London W1T 7NF, UK. ${ }^{2}$ The School of Nursing, Midwifery and Social Work, University of Manchester, Manchester M13 9PL, UK. ${ }^{3}$ Derby Teaching Hospitals NHS Foundation Trust, Derby DE1 2QY, UK. ${ }^{4}$ Department of Statistical Science, UCL, London WC1E $7 \mathrm{HB}, \mathrm{UK}$.

Published online: 03 November 2018

\section{Reference}

1. Kalpakidou AK, Todd C, Keeley V, Griffiths J, Spencer K, Vickerstaff V, Omar RZ, Stone P. The prognosis in palliative care study II (PiPS2): study protocol for a multi-centre, prospective, observational, cohort study. BMC Palliat Care. 2018;17:101

\footnotetext{
* Correspondence: p.stone@ucl.ac.uk

'Marie Curie Palliative Care Research Department, Division of Psychiatry, UCL, 6th Floor, Maple House, 149 Tottenham Court Road, London W1T 7NF, UK Full list of author information is available at the end of the article
}

(c) The Author(s). 2018 Open Access This article is distributed under the terms of the Creative Commons Attribution 4.0 International License (http://creativecommons.org/licenses/by/4.0/), which permits unrestricted use, distribution, and reproduction in any medium, provided you give appropriate credit to the original author(s) and the source, provide a link to the Creative Commons license, and indicate if changes were made. The Creative Commons Public Domain Dedication waiver (http://creativecommons.org/publicdomain/zero/1.0/) applies to the data made available in this article, unless otherwise stated. 